\title{
Research on the Exertion of Information Technology Superiority in
}

\section{Economic Management}

\section{Qingming Liu}

\author{
School of Marxism, Wuhan Textile University, Wuhan, Hubei,China. 430073
}

\section{Email:94524109@qq.com}

\begin{abstract}
With the development of information technology, it's shown that information technology can better serve the management work of the enterprise by integrating and dealing with many types of information, hence promoting the favorable development of the enterprise at a deeper level. With rapid development of China's economy, information construction optimization in economic management has become the key to improve the competitiveness of Chinese enterprises. This paper analyzes the present situation of information technology in economic management from the viewpoint of informatization, and discusses its application optimization strategy.
\end{abstract}

Keywords: Economic management, information technology, advantage, application

\section{Introduction}

With the rapid development of social economy and science and technology, information technology has been widely used in the economic management of enterprises. It has changed the development mode of economic management to a great extent, raised the level of economic management. In this context, in order to further sustainable development, it is necessary for the enterprise to improve information management, modern information technology will be applied to the management of enterprises, especially in enterprise economic management, which can not only achieve management innovation, but also to achieve technological innovation. Therefore, the enterprise management must conform to the trend of the times and attach importance to the application of information technology in the enterprise management.

\section{The Application of Information Technology in Economic Management}

2.1 The Connotation and Characteristics of Modern Information Technology. Information is based on data, and information technology is the data acquisition, transmission, processing, storage, display and application technology, it is supported by computer and communication technology to obtain, process, store, transform, display and transmission of text, and integrated treatment. Its analysis can help people make scientific and reasonable judgments and decision-making. Information technology covers a variety of disciplines, such as science, technology, engineering and management.

The main characteristics of modern information technology are low-cost, interactive and cross-regional and so on. Modern enterprises get the full realization of computerization management through the information technology expert system, office automation and intelligent systems. In the daily economic management activities, you can simplify the original complex economic management by clicking the mouse and entering the data. The application of modern information technology in the process of enterprise's daily economic management can effectively save human resources, reduce the cost of enterprises and improve the management efficiency. 
Interaction is one of the biggest differences between modern information technology and traditional technology. Traditional technology focus on the transmission of information, but modern information technology will focus on interaction exchanges between enterprises and staff. It can enable managers to understand the economic structure, personnel structure and transaction content of enterprises at different levels. Advanced enterprise innovative management methods and business philosophy can keep abreast of business activities, production processes, design concepts, production path and management. Modern information technology can also be widely used to achieve business to business, business to customer information exchange between the formation of non-contact entities, thereby improving operational efficiency. Finally, cross-regional. The application of modern information technology in enterprise economic management is not limited by time and region. It breaks through the shackles of traditional technology in time and space. It can fully understand cooperative enterprises and competitive enterprises through information contact and obtain valuable commercial information to enhance Enterprise management level, to ensure the sustainable development of enterprises.

2.2 The Problems of Exerting the Superiority of Information Technology in Economic Management. The lack of attention to information technology: Under the restriction of the traditional concept, the leadership and staff of some enterprises or institutions are not fully aware of the important value of information technology in economic management, so they pay little attention to the application of information technology . Some leaders simply believe that the economic management based on information technology is to operate computer, so they do not want to carry on the complex information construction.

Network security environment is unstable: Enterprises neglect information security issues in the process of information-related network construction for a long time. Neither specialized personnel for information security nor information security knowledge leads to little security measures. Thus, some enterprises are short of network security capabilities. Such as some management personnel store secret enterprise economic data to the internet computer. When using the computer, never updating virus database, patching the system to avoid the system hacking.

Information technology staff needs specialization: Due to inadequate attention to the application of information technology, personnel training is lagging behind. At present, economic management talents with information technology skills is scarce, can not meet the needs of enterprises or tap the advantages of information technology, such as large data, cloud storage and other modern information technology. The little understanding of information technology will hinder the effective development of economic management to some extent and go against business development.

\section{The Superiority of Information Technology in Economic Management}

3.1 Reduce errors, improve accuracy. Under normal circumstances, there is a lag between the information preparation and issue in the time, and the use of information technology allows information from the input, processing and output in a unified system, which can avoid the error of manual statistical calculation; on the other hand, through the network we can check the data at any time, even if the error can be corrected in accordance with procedures to avoid the lag caused by manual management of various problems, so the application of information technology can reduce errors and improve accuracy.

3.2 Conducive to scientific decision-making. Modern information technology in the full application of enterprise information and transactions, the information can be shown on the network, and can be effective within the enterprise decision-making, in the information sharing case, within the enterprise all employees can learn more about the development of enterprises, to understand the 
direction of enterprise development, increase the transparency and openness of corporate governance. In addition, when employees can fully understand the internal enterprise information and management, the enterprise's economic management methods or models to make their own recommendations, to improve staff participation in the active management of enterprises at the same time, help to improve the enterprise management mode, improve enterprise management efficiency. At the same time, the application of information technology, all the economic management factors into a unified framework for economic management to provide more comprehensive data, is conducive to scientific and rational decision-making.

3.3 Improve the efficiency of economic management. Modern information technology has the characteristics of large flow and fast circulation, which can be widely used in the process of economic management to shorten the transmission and circulation time of information effectively, reduce the transmission and circulation of information, improve the economic management efficiency of enterprise, realize the enterprise's high-speed operation is of great significance. The use of modern information technology can help enterprises more comprehensive and professional access to a variety of internal and external information to help companies understand the development of the industry, at the same time to make more scientific and effective decision-making. through the network of information exchange, The internal departments of enterprises and institutions speed up information transfer, help standardize management processes, and improve economic management efficiency. Business sector can improve work efficiency and service quality through the external network and customer communication.

3.4 Help to improve the quality of service. In the traditional management mode, much human intervention factors tend to breed black-box operation and other issues, and seriously affect the economic security of enterprises. But in the information management system, each person's authority is strictly defined into the database with passwords, different people with different passwords, thus improving data security and reduce fraud over the right behavior.

\section{The concrete measures of exerting the superiority of economic management informationization}

4.1 Improve the application of information technology awareness. Thought is the guide to action", only the correct concept can produce the correct action. The leaders and staff of enterprises and institutions should highlight the great role of information technology in economic management, and then put it firmly into practice in the course of action, and strive to promote the construction of information technology, improve the information management system, And making full use of this information technology platform can promote the efficient operation of economic management for the development of enterprises and institutions.

Information technology in the enterprise's economic management plays an important role in the premise, it's essential to improve the management and further strengthen the information technology in the economic management process so that can effectively improve the management of enterprises in the ideological understanding of information technology. The related information management software has a full understanding and awareness, they can realize the information construction advantages and importance. When enterprise managers shed more light on information technology application to economic management, they will invest more funds to speed up the economic management of information technology.

4.2 Focus on training talents of economic management of information technology. The high-level, quality personnel for the economic management of information technology applications play a very important role, therefore, enterprises should pay attention to staff training, strengthen 
information technology and economic management knowledge, improve their quality and level. the following aspects are references : First, to extend the outstanding staffs potential to their full, especially in the enterprise's economic management process, the training on the modern enterprise information technology should be strengthened, so that outstanding employees can better use of modern information technology for the economy management of the good start of the work . Secondly, we should enhance the knowledge acquisition of modern employees by means of staff training, expert lectures and academic exchanges, and update their knowledge structure so as to perfect the knowledge of economic management on the basis of mastering modern information technology, Employees can better complete their own work and make more contributions to the enterprises. Finally, the introduction and absorption of quality composite talents can rapidly improve the technical level for enterprises and institutions, thus offer reliable protection for the effective application of information technology.

4.3 Constructing the Network Security Safeguard for Economic Management. It's necessary for Enterprise economic management to raise awareness of its own network security issues, because a lot of economic management information may leak out through the network, so improving employee information security awareness for the healthy development of enterprise economy has an undoubted significance and role. This requires a series of initiatives to complete the establishment of information security system. Such as the implementation of network information security rectification project implementation in order to clear the network of insecurity; to improve staff awareness of network security and network malicious behavior by information security training; Introducing outstanding network security technical personnel can guarantee enterprises production and operation.

4.4 Promote hardware construction. First of all, the enterprise information infrastructure should be improved, and the leadership of the economic management of information technology should be improved as well, which is the modern economic management information technology infrastructure optimization and the premise. Second, the construction of a systematic management system is a must. The management system is a necessary condition for the effective development of economic management informization. Finally, to further strengthen the economic management of enterprise information equipment updates, where conditions permit, and constantly optimize the modern economic management hardware facilities, to achieve economic facilities, information, and continuously build features consistent with the characteristics of large economic data management equipment. These hardware construction need a lot of capital investment, which facilitates the orderly development of economic management information construction.

\section{Conclusions}

Economic management is an important part of modern enterprise management, and its management efficiency directly affects the overall management level and efficiency of enterprises, which is of great value to the development of enterprises. Therefore, in order to improve the quality and level of economic management of enterprises, modern enterprises should introduce and fully apply advanced modern information technology, which boosts its favorable influences on improving the management level and efficiency of enterprises so that enterprises can be undefeated in the increasingly fierce market competition. 


\section{References}

[1] Cao MiaoSun. Restructure of the Economic Management Framework in the Information Age Environment [J]. Journal of Business Economics, 2016 (07): 119-121.

[2] Wang Yunhua. Analysis on the Economic Management Behavior of Public Institutions [J]. China Business Review, 2016 (07) : 45-47.

[3] DONG Wen-yang, ZHANG Wen-xiu, HAN Fang-fang, et al. Some ideas on using health care technology to strengthen health economic management [J]. Medical Information, 2015(01): 17-18.

[4]YANG Chao-Ran. Application of Information Technology in Economic Management Process [J]. Modern Business, 2015 (03): 55-56.

[5] Sha Zhiyun. Application of Computer Technology in Modern Economic Management System [J] .Trade Practice, 2015 (13): 197-198

[6] Li Chen. Analysis of information technology in enterprise management applications [J]. SME Management and Technology, 2013, (15): 27-28.

[7] Zhang Hao. Strengthen the information technology to promote enterprise management innovation [J]. China Science and T

[8] Liu Lanjuan, "Computer Application in Economic Management", Tsinghua University Press (2013) 